\title{
An Electrochemical Sensor Based on ion Imprinted PPy/rGO Composite for Cd(II) Determination in Water
}

\author{
Shiwei Hu ${ }^{1}$, Guowei Gao ${ }^{1,2, *}$, Ye Liu ${ }^{l}$, Jingfang $\mathrm{Hu}^{1,2, *}$, Yu Song ${ }^{1,2}$, Xiaoping Zou ${ }^{1,2}$ \\ ${ }^{1}$ Beijing Key Laboratory for Sensor, Beijing Information Science \& Technology University, Beijing \\ 100101, China \\ ${ }^{2}$ MOE Key Laboratory for Modern Measurement and Control Technology, Beijing Information Science \\ \& Technology University, Beijing 100192, China \\ *E-mail: jfhu@bistu.edu.cn, ggw@bistu.edu.cn
}

doi: $10.20964 / 2019.11 .56$

Received: 30 July 2019 / Accepted: 12 September 2019 / Published: 29 October 2019

\begin{abstract}
This study reports a novel electrochemical sensor based on ion imprinted polypyrrole and reduced graphene oxide (PPy/rGO) composite for trace level determination of $\mathrm{Cd}(\mathrm{II})$ in water. The ion imprinted polymer (IIP) modified electrode (IIP/rGO/GCE) was fabricated with two steps. First, reduced graphene oxide (rGO) was electrodeposited on the surface of GCE by cyclic voltammetry (CV), and then $\mathrm{IIP} / \mathrm{rGO} / \mathrm{GCE}$ was obtained by electropolymerization of pyrrole and template $\mathrm{Cd}(\mathrm{II})$ on the surface of rGO and the imprinted template $\mathrm{Cd}(\mathrm{II})$ ions were removed by electrochemical method. The morphology of IIP/rGO/GCE was characterized by scanning electron microscopy (SEM) and transmission electron microscopy (TEM). Experimental conditions such as deposition time, $\mathrm{pH}$, supporting electrolyte, accumulation time and potential were optimized for the sensor performance. Square wave anodic stripping voltammetry (SWASV) was applied for the determination of Cd(II). As expected, there is a significant difference in the Cd(II) stripping peak response between IIP/rGO/GCE and NIP/rGO/GCE. Under the optimized conditions, the sensor has a good linearity in the range from 1 to $100 \mu \mathrm{g} / \mathrm{L}$. The limit of detection is $0.26 \mu \mathrm{g} / \mathrm{L}(\mathrm{S} / \mathrm{N}=3)$. From the experimental results, the sensor has superior stability, reproducibility and selectivity. The sensor has been successfully applied to the determination of trace level Cd(II) in spiked real water samples.
\end{abstract}

Keywords: Cd(II) determination; ion imprinted polymer (IIP); PPy/rGO composite; electrochemical sensor; square wave anodic stripping voltammetry

\section{$\underline{\text { FULL TEXT }}$}

(C) 2019 The Authors. Published by ESG (www.electrochemsci.org). This article is an open access article distributed under the terms and conditions of the Creative Commons Attribution license (http://creativecommons.org/licenses/by/4.0/). 